\title{
Reliability and Validity of the Chinese Version of the Addiction Severity Index
}

\author{
Wei Luo ${ }^{*}$, Zunyou $\mathrm{Wu}^{*}$, and Xiaoli Wei ${ }^{\dagger}$ \\ ${ }^{*}$ National Center for AIDS/STD Control and Prevention, Chinese Center for Disease Control and \\ Prevention, Beijing \\ † Division of AIDS Control and Prevention, Municipal Center for Disease Control and Prevention, \\ Xi'an, Shanxi Province
}

\section{Abstract}

Objective-The addiction severity index (ASI) is one of the most commonly used assessment devices used in the field of substance abuse. There is no research on the Chinese version of the newest scale in China so far. The study is to validate a Chinese adaptation of the fifth version of the ASI instrument.

\begin{abstract}
Method-The Chinese version of the ASI was translated and revised based on the fifth English version. Psychometric properties of the ASI were tested through face-to-face interviews. Five hundred and twenty six patients who had been in the methadone maintenance treatment clinic in Xi' an City, Shanxi Province for more than three months were interviewed by three trained interviewers. About $83 \%$ of the 526 interviewees were male. Analysis of internal consistency, reliability measures including test-retest and inter-rater correlation, and criterion validity were conducted.
\end{abstract}

Results-Across seven domains of the Chinese version of the ASI, Cronbach's $\alpha$ coefficients ranged from 0.44 to 0.79 , test-retest correlation coefficients ranged from 0.68 to 0.84 , inter-rater correlations ranged from 0.74 to 0.98 , and the criterion validity was 0.5 .

Conclusion-The Chinese version of the ASI has acceptable reliability and validity in a sample of drug-dependent patients.

\section{Keywords}

Addiction Severity Index; reliability; validity

\section{INTRODUCTION}

The Addiction Severity Index (ASI) is one of the most widely used semi-structured interviews in the field of substance abuse, 1 having been translated into more than thirteen languages. $2^{-}$ 6 It has been used for over twenty-six years to explore the problems of addiction patients and to measure illness outcomes and treatment effectiveness in seven different areas. In recent years, the ASI has been increasingly used for special sub-groups of drug users such as homeless persons, 7 pregnant and postpartum women (ASI-F) ${ }^{2}$ and adolescents (T-ASI). 8

Correspondence to: Zunyou Wu, National Centre for AIDS/STD Control and Prevention, Chinese Centre for Disease Control and Prevention, 27 Nanwei Road, Xuanwu District, Beijing 100050, China. Tel: 86-10-63165758. Fax: 86-10-63165865. wuzy@263.net. 
Methadone maintenance treatment (MMT) has been considered one of the best practices in the treatment for opiate dependence. ${ }^{9}$ In addition to decreasing the use of drugs, MMT can also decrease both drug-related crimes as well as the transmission of diseases such as HIV. The first MMT program in China began in 2004 in order to prevent HIV transmission through drug use. However, there are many problems associated with MMT clinics programs, including their management and evaluation. It is therefore particularly importance to study the Chinese version of the ASI to assess the effectiveness of MMT programs.

Findings of methodological studies showed that test-retest reliability of the ASI was quite good. Butler and colleagues found Pearson correlations ranging from 0.62 to $0.95 .{ }^{10}$ The inter-rater reliability was also high.1 Studies reported that internal consistency measured by Cronbach's $\alpha$ coefficient ranged from 0.62 for the legal area category to 0.93 for the medical area category. $2,11^{-13}$ Studies conducted among drug users confirmed good validity of the ASI. Hendriks and colleagues found that the correlation between psychiatric sub-scale of ASI and Symptom Checklist-90 (SCL-90) was 0.54. ${ }^{4}$

The purpose of this study was to test the reliability and the validity of the Chinese version in a sample of MMT patients.

\section{METHOD}

\section{Setting and participants}

The study was conducted in five MMT clinics in Xi' an city, Shanxi Province. All participants had been in MMT for more than three months when the study began. Exclusion criteria included severe mental or physical deterioration. This study was approved by the Ethics Committee of the China CDC and informed consent was given by all patients.

\section{Instrument}

The ASI assesses the severity of addiction and need for treatment in seven areas, each reflecting a separate problem area of drug/alcohol abuse: (1) medical status; (2) employment and social support; (3) drug use; (4) alcohol use; (5) legal status; (6) family and social relationships; (7) psychiatric status. The Chinese version of the ASI was based on items from the fifth English version. ${ }^{14}$ It was translated by two independent translators specializing in different areas of research and revised by editors specializing in addiction research. The result was then translated back into the original language and compared with the English version by native Englishspeaking editors. In the interest of international comparability, only the necessary, minimal changes were made to the original questionnaire. The changes made were mainly based on unique Chinese linguistic and socio-cultural factors such as wording or expression style, criminal categories, and compliance with legal regulations, etc. Compared with the original scale, two items in the legal status area was deleted and two other items in the employment and social support area were replaced by two new items. One separate section was added for clinical purposes which addressed HIV risk factors, such as needle sharing and unprotected sex. Reliability and validity of this section was not evaluated since it did not interfere with the ASI Composite Scores (CSs) scoring. Item numbering remained similar to the ASI (5th English version).

\section{Procedures and Analysis}

Three interviewers (one researcher and two doctors) participated in the study. Each of the two doctors involved had several years of psychiatric clinic experience. All of the interviewers completed a 1-day training program that reviewed the ASI manual, thorough discussions and practice sessions. 
During the face-to-face interview, patient and interviewer rated the level of severity using separate rating scales for each of the seven ASI areas. The patient uses a scale of 0-4 to rate (1) how serious he/she thinks the problem is, and (2) how important he/she considers it is to receive treatment or counseling. The interviewer uses a nine-point scale for each area to rate the patient's requirement for further treatment. This assessment relies on the patient's symptoms at that time and the patient's own subjective evaluation. The interviewer has to decide how much additional treatment the patient needs in each of the areas.

The data were assessed according to international practice.15 Composite scores were calculated for all seven areas. ${ }^{16}$ The inter-rater reliability, test-retest reliability and internal consistency among the reliability indicators were examined. Inter-rater reliability was established involving one primary interviewer questioning the patient and the other two observing and scoring independently in 80 separate interviews. The stability of the measures over time was evaluated by comparing CSs between the first and second interviews with a time interval of seven days. Correlations were calculated between interviewers' severity ratings (ISRs) and CSs, between CSs across different areas, as well as between 'critical items' constituting the different areas and the CSs within sections.

The data were analyzed using SPSS for Windows 13.0. Internal consistency was calculated by Cronbach's $\alpha$ test, with a value of 0.6 and higher considered as acceptable. ${ }^{2}$ Spearman correlation test was used to calculate reliability coefficients and validity of similar scales. The significance level ( $\mathrm{p}$ value) was set at 0.05 .

\section{RESULTS}

\section{Demographic characteristics}

Five hundred and thirty-one patients were randomly chosen and approached while waiting for their methadone dose. Five interviews were abandoned because of incomplete information. Demographic comparisons between the final sample $(\mathrm{N}=526)$ and 331 admissions preceding the study were statistically nonsignificant.

The sample comprised 438 males and 88 females. The average age was 37.8 years (age range: $21-53 ; \mathrm{SD}=6.0$ ). A majority of the drug users participating in the investigation $(59.3 \%)$ had finished junior middle school, while $4 \%$ had a college-level education or higher. Most were unemployed $(82.1 \% ; \mathrm{n}=432)$. Fifty-eight $(11 \%)$ patients reported abusing alcohol in their lifetime while only thirty-six $(6.8 \%)$ had alcohol problems during the 30 days prior to the interview (Table 1).

\section{Internal Consistency}

The reliability of the sub-scales covering the ASI problem areas in our sample was considered acceptable except for the legal sub-scale (Cronbach's $\alpha=0.44$ ). The value of the other six domains ranged from $0.63-0.79$ (Table 2 ). The legal domain failed to demonstrate good internal consistency in this sample of patients.

\section{Test-retest reliability}

The CSs before and after a week's interval were highly correlated. Spearman's $\rho$ correlations for the test-retest were high (0.68-0.84; Table 3$)$. There was no significant difference between the two interviews, indicating that the Chinese version of the ASI was stable. 


\section{Inter-rater reliability}

All severity ratings and composite scores had good correlations ranging from 0.74 to 0.98 (Table 4). Overall, the composite scores had higher coefficient (mean $=0.93)$ than the severity ratings $($ mean $=0.86)$.

\section{Relationship between Interviewers' Severity Ratings and Composite Scores}

Table 5 showed the correlation between the ISRs and the CSs. In most areas the correlation was high, ranging from $0.67-0.98$.

\section{Relationship between Composite Scores}

In order to demonstrate that different ASI domains reflected distinct problem areas with minimal overlaps, correlations between domains were evaluated (Table 6). The correlation coefficient was quite low.

\section{Relationship between items and Composite Scores}

Several items were chosen in each of the seven domains as indicators of problem severity and the correlations between these items and the CSs were presented in Table 7. In most cases, items were significantly correlated with the CSs. The only correlation not of statistical significance was that between prescribed medication for any psychological/emotional problem in last 30 days and the psychiatric score.

\section{Criterion validity of the Composite Scores}

Table 7 presented the correlation between the CSs and the criterion measurement. The correlation of the psychiatric score with $S C L-90$ was 0.5 , the correlation of the family/social score with the Family Adaptability and Cohesion Evaluation Scale $\alpha$-Chinese Version (FACES $\alpha-C V)$ was 0.45 .

\section{DISCUSSION}

The findings with the Chinese version of the ASI were consistent with many other studies.4, 14, ${ }^{18}$ However, the internal consistency was moderate to weak for the 'legal' domain. This was likely because of the modification to the original items in this area in terms of Chinese socio-cultural background and drug-related criminal categories. Two of the five critical items used to calculate the CSs were abandoned ("whether presently awaiting charges, trial or sentencing' and 'importance of counseling or referral for legal problems'). For the other six domains of the ASI, the Cronbach's $\alpha$ coefficient was acceptable and similar to results found in the literature. ${ }^{19-} 21$

The test-retest reliability 10,22 and inter-rater reliability also corresponded to the values found in other studies.1,23 The CSs coefficient being higher than the ISRs coefficient was also consistent (Gerevich et al., 2005). Greater agreement among the CSs would be expected because these scores were based on mathematical formulas and did not take into account the interviewer's subjective interpretation. Criterion validity of the CSs was acceptable. The correlation between CSs and SCL-90 in the study was similar to Hendriks' findings. ${ }^{4}$

Correlations between domains of the ASI were generally low. The result indicated a relative independence between domains. This independence has been found in other studies. ${ }^{12,17} \mathrm{CSs}$ and items within the same domain were significantly correlated, confirming the validity of the ASI original scale construct. 
One limitation in this study involves the alcohol domain. Ninety-three percent of the interviewees hadn't experienced alcohol problems in the last 30 days because the patients were prohibited from drinking alcohol during treatment in MMT clinic. This may have led to an underestimation of the alcohol problems of the patients, which would also have an effect on the evaluation of the reliability and validity of the scale.

Overall, this Chinese version of the ASI appeared to have acceptable reliability and validity. The scale was demonstrated to be a valid instrument for Chinese drug-dependent patients and can be used widely in addiction research areas such as assessing addiction of patients in methadone maintenance patients and assessing effectiveness of the treatment.

\section{Acknowledgments}

Authors thank Ying Wang and Rui Zhang for their contribution to the interviewing work, thank Wei Jia, Quncai Zhang, Hong Yan, and Liangliang Li for their organizational work, thank. Jianhua Li for his comments and suggestions, thank Adrian Liau for editing the manuscript.

Supported by the International Clinical Operational and Health Services Research and Training Award (ICOHRTA) AIDS/TB, Grant \#U2RTW006917 and U2RTW006918, funded by the US National Institutes of Health, the Fogarty International Center, the National Institute of Drug Abuse and the National Institute of Mental Health.

\section{References}

1. McLellan AT, Luborsky L, Woody G, et al. An improved diagnostic evaluation instrument for substance abuse patients: The Addiction Severity Index. J Nerv Ment Dis 1980;168:26-33. [PubMed: 7351540]

2. Gerevich J, Bacskai E, Ko J, et al. Reliability and validity of the Hungarian version of the European Addiction Severity Index. Psychopathology 2005;38:301-309. [PubMed: 16224203]

3. Krenz S, Dieckmann S, Favrat B, et al. French version of the Addiction Severity Index (5th Edition): validity and reliability among Swiss opiate-dependent patients. French validation of the Addiction Severity Index. Eur Addict Res 2004;10:173-179. [PubMed: 15367819]

4. Hendriks VM, Kaplan CD, Limbeek JV, et al. The Addiction Severity Index: reliability and validity in a Dutch addict population. J Subst Abuse Treat 1989;6:133-141. [PubMed: 2746712]

5. Scheurich A, Muller MJ, Wetzel HA, et al. Reliability and validity of the German version of the European Addiction Severity Index (EuropASI). J Stud Alcohol 2000;61:916-919. [PubMed: 11188499]

6. EMCDDA. EIB home: EIB categories: Browse Treatment:Needs:Addiction Severity Index. 2005. Available at: http://eib.emcdda.europa.eu/index.cfm? fuseaction=public. Content \&nNodeID=3538\&sLanguageISO=EN

7. Argeriou M, McCarty D, Mulvey K, et al. Use of the Addiction Severity Index with homeless substance abusers. J Subst Abuse Treat 1994;11:359-365. [PubMed: 7966506]

8. Brodey BB, Rosen CS, Winters KC, et al. Conversion and validation of the Teen-Addiction Severity Index (T-ASI) for Internet and automated-telephone self-report Administration. Psychol Addict Behav 2005;19:54-61. [PubMed: 15783278]

9. Lisa A. The efficacy of methadone maintenance interventions in reducing illicit opiate use, HIV risk behavior and criminality: a meta-analysis. Addiction 1998;93:515-532. [PubMed: 9684390]

10. Butler SF, Budman SH, Goldman RJ, et al. Initial validation of a computer-administered Addiction Severity Index: the ASI-MV. Psychol Addict Behav 2001;15:4-12. [PubMed: 11255937]

11. Rosen CS, Henson BR, Finney JW, et al. Consistency of self-administered and interview-based Addiction Severity Index composite scores. Addiction 2000;95:419-425. [PubMed: 10795362]

12. Leonhard C, Mulvey K, Gastfriend DR, et al. The Addiction Severity Index: a field study of internal consistency and validity. J Subst Abuse Treat 2000;18:129-135. [PubMed: 10716096] 
13. Bovasso GB, Alterman AI, Cacciola JS, et al. Predictive validity of the Addiction Severity Index's composite scores in the assessment of 2-year outcomes in a methadone maintenance population. Psychol Addict Behav 2001;15:171-176. [PubMed: 11563793]

14. McLellan AT, Kushner H, Metzger D, et al. The fifth edition of the Addiction Severity Index. J Subst Abuse Treat 1992;9:199-213. [PubMed: 1334156]

15. McDermott PA, Alterman AI, Brown L, et al. Construct refinement and confirmation for the Addiction Severity Index. Psychol Assess 1996;8:182-189.

16. McGahan, PL.; Griffith, JA.; Parente, R., et al. Addiction severity index: Composite scores manual. Philadelphia: Treatment Research Institute; 1986.

17. McLellan AT, Luborsky L, Cacciola J, et al. New data from the Addiction Severity Index: reliability and validity in three centers. J Nerv Ment Dis 1985;173:412-423. [PubMed: 4009158]

18. Hodgins D, El-Guebaly N. More data on the Addiction Severity Index reliability and validity with the mentally ill substance abuser. J Nerv Ment Dis 1992;180:197-201. [PubMed: 1588339]

19. Zanis DA, McLellan AT, Corse S. Is the addiction severity index a reliable and valid assessment instrument among clients with severe and persistent mental illness and substance abuse disorders. Community Ment Health J 1997;33:213-227. [PubMed: 9211041]

20. Appleby L, Dyson V, Altman, et al. Assessing substance use in multiproblem patients: reliability and validity of the Addiction Severity Index in a mental hospital population. J Nerv Ment Dis 1997;185:159-165. [PubMed: 9091597]

21. Comfort M, Zanis DA, Whiteley MJ, et al. Assessing the needs of substance abusing women: psychometric data on the psychosocial history. J Subst Abuse Treat 1999;17:79-83. [PubMed: 10435254]

22. Cacciola JS, Koppenhaver JM, Mckay JR, et al. Test-Retest reliability of the lifetime items on the Addiction Severity Index. Psychol Assess 1999;11:86-93.

23. Mäkelä K. Studies of the reliability and validity of the Addiction Severity Index. Addiction 2004;99:398-410. [PubMed: 15049734] 


\section{Table 1}

Demographic characteristics of the study population

\begin{tabular}{lll}
\hline Variable & Statistic & n \\
\hline Age & $37.84 \pm 6.04$ & 526 \\
Gender & & \\
Male & $83.3 \%$ & 438 \\
Female & $16.7 \%$ & 88 \\
Occupation & & 31 \\
Owner & $5.9 \%$ & 6 \\
Service & $1.1 \%$ & 432 \\
Unemployed & $82.1 \%$ & 8 \\
Staff & $1.5 \%$ & 35 \\
Worker & $6.7 \%$ & 12 \\
Farmer & $2.3 \%$ & 2 \\
Other & $0.4 \%$ & 40 \\
Education & & 272 \\
Primary School or lower & $7.6 \%$ & 193 \\
Junior Middle School & $51.7 \%$ & 21 \\
Senior Middle School & $36.7 \%$ & 56 \\
College or higher & $4.0 \%$ & \\
Marital Status & & 287 \\
Single & $34.8 \%$ & \\
Married & $54.6 \%$ & \\
Divorced/Widowed & $10.7 \%$ & \\
\hline
\end{tabular}


Table 2

Cronbach's $\alpha$ coefficient $(n=526)$

\begin{tabular}{lc}
\hline ASI scale & $\boldsymbol{\alpha}$ \\
\hline Medical & 0.73 \\
Employment & 0.63 \\
Alcohol & 0.68 \\
Drug & 0.67 \\
Legal & 0.44 \\
Family/social & 0.79 \\
Psychiatric & 0.73 \\
\hline
\end{tabular}


Table 3

Test-retest: Spearman's $\rho$ correlations of composite scores $(n=51)$

\begin{tabular}{ll}
\hline ASI scale & $\mathbf{C S s}(\boldsymbol{\rho})$ \\
\hline Medical & $0.84^{* *}$ \\
Employment & $0.75^{* *}$ \\
Alcohol & $0.75^{* *}$ \\
Drug & $0.70^{* *}$ \\
Legal & $0.72^{* *}$ \\
Family/social & $0.80^{* *}$ \\
Psychiatric & $0.68^{* *}$ \\
\hline${ }^{* *}<0.01$ &
\end{tabular}


Table 4

Inter-rater reliability: $\alpha$ coefficient of composite scores and interviewers' severity ratings $(n=80)$

\begin{tabular}{lcc}
\hline ASI scale & CSs $(\boldsymbol{\alpha})$ & ISRs $(\boldsymbol{\alpha})$ \\
\hline Medical & 0.98 & 0.94 \\
Employment & 0.97 & 0.91 \\
Alcohol & 0.94 & 0.85 \\
Drug & 0.88 & 0.82 \\
Legal & 0.87 & 0.74 \\
Family/social & 0.94 & 0.89 \\
Psychiatric & 0.93 & 0.88 \\
\hline
\end{tabular}


Table 5

Spearman's $\rho$ correlations between severity ratings and composite scores $(n=526)$

\begin{tabular}{ll}
\hline ASI scale & Correlation \\
\hline Medical & $0.73^{* * * *}$ \\
Employment & $0.67^{* * * *}$ \\
Alcohol & $0.92^{* * *}$ \\
Drug & $0.86^{* * *}$ \\
Legal & $0.98^{* * *}$ \\
Family/social & $0.94^{* * *}$ \\
Psychiatric & $0.71^{* * *}$ \\
\hline$* * *$ \\
$P<0.001$ &
\end{tabular}


Table 7

Correlation coefficients between items and composite scores

\begin{tabular}{|c|c|}
\hline Items & Correlation coefficients \\
\hline \multicolumn{2}{|l|}{ Medical status $(n=526)$} \\
\hline Days experienced medical problems(last 30 days) & $0.86^{* * *}$ \\
\hline Troubled by medical problems(last 30 days) & $0.69^{* * *}$ \\
\hline Treatment importance for the medical problems & $0.73^{* * *}$ \\
\hline \multicolumn{2}{|l|}{ Employment/social support $(n=526)$} \\
\hline If vehicle available when going out & $-0.14^{* *}$ \\
\hline If the vehicle convenient when going out & $-0.32^{* * *}$ \\
\hline Days paid for work (last 30 days) & $-0.77^{* * *}$ \\
\hline Money received from employment (last 30 days) & $-0.91^{* * *}$ \\
\hline \multicolumn{2}{|l|}{ Drugs $(n=526)$} \\
\hline Heroin use (last 30 days) & $0.27^{* * *}$ \\
\hline Days experienced drug problems (last 30 days) & $0.63^{* * *}$ \\
\hline Troubled by drug problems (last 30 days) & $0.67^{* * *}$ \\
\hline Treatment importance for drug problems & $0.57^{* * *}$ \\
\hline \multicolumn{2}{|l|}{ Alcohol $(n=526)$} \\
\hline Alcohol consumption: moderate use (last 30 days) & $0.99^{* * *}$ \\
\hline Alcohol consumption: intoxication (last 30 days) & $0.50^{* * *}$ \\
\hline Days experienced alcohol problems (last 30 days) & $0.46^{* * *}$ \\
\hline Troubled by alcohol problems (last 30 days) & $0.25^{* * *}$ \\
\hline Treatment importance for alcohol problems & $0.22^{* * *}$ \\
\hline Money spent for alcohol (last 30 days) & $0.94^{* * *}$ \\
\hline \multicolumn{2}{|l|}{ Legal $(n=526)$} \\
\hline Severity of present legal problems & $0.88^{* * *}$ \\
\hline days engaged in illegal activities for profit(last 30 days) & $0.39^{* * *}$ \\
\hline Money received from illegal activities (last 30 days & $0.66^{* * *}$ \\
\hline \multicolumn{2}{|l|}{ Family/social relationships $(n=526)$} \\
\hline Satisfied with marital status & $0.87^{* * *}$ \\
\hline Troubled by family problems (last 30 days) & $0.51^{* * *}$ \\
\hline Treatment importance or counseling needs for these family problem & $0.54^{* * *}$ \\
\hline Days experienced serious conflicts with your family (last 30 days) & $0.34^{* * *}$ \\
\hline \multicolumn{2}{|l|}{ Psychiatric $(n=526)$} \\
\hline Experienced serious depression (last 30 days) & $0.66^{* * *}$ \\
\hline Experienced serious anxiety or tension (last 30 days) & $0.47^{* * *}$ \\
\hline Experienced hallucinations (last 30 days) & $0.22^{* * *}$ \\
\hline Experienced trouble understanding, concentrating or remembering (1 & $0.59^{* * *}$ \\
\hline
\end{tabular}




\begin{tabular}{ll}
\hline Items & Correlation coefficients \\
\hline Experienced trouble controlling violent behavior (last 30 days) & $0.34^{* * *}$ \\
Experienced serious thought of suicide (last 30 days) & $0.39^{* * *}$ \\
Attempted suicide (last 30 days) & $0.14^{* *}$ \\
Prescribed medication for any psychological/emotional problem (last 30 days) & 0.08 \\
Days experienced psychological or emotional problems (last 30 days) & $0.95^{* * *}$ \\
Troubled by these psychological or emotional problems (last 30 days) & $0.72^{* * *}$ \\
Treatment importance for these psychological problems & $0.53^{* * *}$ \\
$S C L-90(n=47)$ & $0.5^{* * *}$ \\
$F A C E S \alpha-C V(n=44)$ & $0.45^{* * *}$ \\
\hline$* * \quad P<0.01$, & \\
$* * * 0.001$ &
\end{tabular}

